\title{
Pengaruh E-Commerce Toko Online Fashion Terhadap Kepercayaan Konsumen
}

\author{
Eli Pujastuti*1, Wing Wahyu Winarno ${ }^{2}$, Sudarmawan ${ }^{3}$ \\ ${ }^{1,3}$ Magister Teknik Informatika STMIK AMIKOM Yogyakarta \\ ${ }^{2}$ STIE YKPN Yogyakarta \\ E-mail: " 1 elipujastuti@gmail.com, ${ }^{2}$ maswing@ gmail.com, ${ }^{3}$ sudarmawan@amikom.ac.id
}

\begin{abstract}
Abstrak
E-commerce yang menawarkan banyak kemudahan terhadap konsumen belum tentu berhasil hanya dengan membuat website toko online, namun konsumen secara personal juga akan menilai dan menentukan perilaku apa yang akan diambil berdasarkan penilaian secara subyektif dari konsumen terhadap suatu situs e-commerce, apakah konsumen tersebut akan percaya dan selanjutnya dengan senang hati bertukar informasi pribadi dengan situs $e$ commerce, dan akhirnya mempunyai keinginan untuk bertransaksi atau tidak. Penelitian ini bermaksud menguji pengaruh 3 faktor dalam Trust Building Model (TBM) kaitannya dengan kepercayaan konsumen terhadap e-commerce toko online fashion di Indonesia. Benarkah kepercayaan konsumen di Indonesia disebabkan oleh faktor perceived site quality (kualitas situs yang dirasakan), faktor perceived vendor reputation (reputasi vendor yang dirasakan), dan structural assurance (susunan keamanan) khususnya untuk e-commerce bisnis ke konsumen. Penelitian ini menggunakan Structural Equation Modeling (SEM) untuk menganalisis masingmasing faktor tersebut dengan meneliti 200 responden yang sudah pernah bertransaksi dan belum pernah bertransaksi namun mempunyai keinginan di kemudian hari dan sudah pernah berkunjung ke situs toko online fashion. Hasil dari penelitian ini menunjukkan bahwa kepercayaan konsumen e-commerce toko online fashion di Indonesia sangat dipengaruhi oleh kualitas website dan susunan keamanan yang tersaji melalui website, sedangkan reputasi vendor melalui website tidak signifikan mempengaruhi konsumen untuk bisa lebih percaya pada suatu vendor toko online fashion.
\end{abstract}

Kata Kunci - e-commerce, kepercayaan, kualitas web, reputasi vendor, keamanan web

\begin{abstract}
E-commerce that offers a lot of convenience to consumers uncertain of success simply by making the website an online store, but consumers will personally assess and determine what behavior that consumers will take based on consumer's assessment of an e-commerce site, whether consumer will believe and subsequent gladly exchange personal information with an ecommerce website, and make the transaction or not. This study intends to examine the influence of three factors in the Trust Building Model (TBM) relation with consumer's trust in e commerce online store of fashion in Indonesia. Is it true that consumer's trust in Indonesia is caused by those factors: perceived site quality, perceived vendor reputation, and structural assurance, especially for e-commerce business to consumer. This study used Structural Equation Modeling (SEM) to analyze each of these factors by examining the 200 respondents who had dealings and have never had trade but have willingness to trade later and had ever been to a fashion online store site.
\end{abstract}


The results of this study indicate that consumer's trust in ecommerce online store of fashion in Indonesia is strongly influenced by the quality of the website and structural assurance presented through the website, while the reputation of the vendor through the website does not significantly influence consumers to be more trust in an online fashion store vendors.

Keywords - e-commerce, trust, web quality, vendor reputation, structural assurance

\section{PENDAHULUAN}

E-commerce adalah suatu jenis dari mekanisme bisnis secara elektronis yang memfokuskan diri pada transaksi bisnis berbasis individu dengan menggunakan internet sebagai medium pertukaran barang atau jasa baik antara dua buah institusi (B-to-B) maupun antara institusi dan konsumen langsung (B-to-C)[1]. Dalam e-commerce B-to-C vendor berhubungan langsung dengan konsumen melalui website yang sudah dibangun untuk menyajikan produk virtual yang tidak bisa disentuh oleh konsumen secara langsung. Website B-to-C bisa berupa sebuah toko online dengan berbagai desain, reputasi, dan keamanan yang diintegrasikan untuk menumbuhkan kepercayaan konsumen. Berbagai produk dapat dijual melalui toko online seperti elektronik, gadget, dan fashion. Berbeda dengan toko online elektronik atau gadget yang mempunyai spesifikasi pasti, pada toko online fashion konsumen hanya dapat mengira-ngira dengan deskripsi ukuran, warna, maupun bahan yang tertera sedangkan konsumen tidak tahu pakaian tersebut sudah sesuai dengan keinginan konsumen atau belum.

E-commerce yang menawarkan banyak kemudahan terhadap konsumen belum tentu berhasil hanya dengan membuat website toko online, namun konsumen secara personal juga akan menilai dan menentukan perilaku apa yang akan mereka ambil berdasarkan penilaian mereka terhadap suatu situs e-commerce, apakah konsumen akan percaya dan selanjutnya dengan senang hati bertukar informasi pribadi dengan situs e-commerce, dan bertransaksi atau tidak. Para pembeli online sangat hati-hati, dan dengan ancaman kecurangan online, mereka memiliki alasan untuk berperilaku demikian. Pada dasarnya, banyak pembeli tidak percaya pada situs, kecuali jika perusahaan dapat membangun kepercayaan pengunjung atas situs terkait. Pengunjung mulai mengevaluasi kredibilitas situs begitu mereka memasukinya[2].

Kepercayaan adalah kemauan seseorang untuk bertumpu pada orang lain dimana kita memiliki keyakinan padanya. Kepercayaan merupakan kondisi mental yang didasarkan oleh situasi seseorang dan konteks sosialnya. Ketika seseorang mengambil suatu keputusan, ia akan memilih keputusan berdasarkan pilihan dari orang-orang yang lebih dapat ia percaya daripada yang kurang dipercayai [3]. Kepercayaan konsumen terhadap e-commerce sangat penting karena mempengaruhi jumlah transaksi online. Azam (2013) mengatakan dalam penelitiannya bahwa tidak akan ada transaksi yang terjadi dalam perdagangan online tanpa adanya kepercayaan. Karena kepercayaan pada perdagangan online lebih dibutuhkan daripada perdagangan offline (nyata). Pada perdagangan online, pelaku transaksi tidak bertemu langsung secara fisik dan produk yang dijual pun tidak bisa dilihat dan disentuh secara langsung. Konsumen bahkan tidak tahu apakah penjual dalam toko online adalah orang yang benar-benar memiliki barang dagangannya dan pedagang juga tidak selalu yakin bahwa pembayarannya akan sampai ke rekening penjual [4].

Penelitian yang dilakukan oleh McKnight (2002) [5], seorang asisten professor di The Eli Broad College of Business at Michigan State University USA, mengemukakan bahwa ada sebuah model yang berisi faktor pembangun kepercayaan seorang konsumen terhadap ecommerce. Model tersebut disebut Trust Building Model (TBM). Penelitian ini bermaksud menguji pengaruh 3 faktor dalam Trust Building Model (TBM) kaitannya dengan kepercayaan konsumen terhadap e-commerce toko online fashion di Indonesia. Benarkah kepercayaan konsumen di Indonesia disebabkan oleh faktor perceived site quality (kualitas situs yang dirasakan), faktor perceived vendor reputation (reputasi vendor yang dirasakan), dan structural assurance (susunan keamanan) khususnya untuk e-commerce bisnis ke konsumen. Penelitian ini 
menggunakan Structural Equation Modeling (SEM) untuk menganalisis masing-masing faktor tersebut dengan meneliti 200 responden yang sudah pernah bertransaksi dan belum pernah bertransaksi namun mempunyai keinginan di kemudian hari dan sudah pernah berkunjung ke situs toko online fashion.

Terdapat penelitian-penelitian terkait yang juga meneliti kepercayaan konsumen terhadap ecommerce. Penelitian lain tersebut yaitu:

a) Pengaruh Privasi dan Kepercayaan terhadap Internet pada Perilaku Pembelian Online [6]. Penelitian terkait yang pertama ini ditulis oleh pratama. Tujuan dari penelitian pratama ini adalah untuk menganalisis pengaruh privasi dan kepercayaan terhadap pembelian online dengan berdasar pada Theory of Planned Behavior (TPB). Menggunakan variabel aspek privasi dan kepercayaan, control perilaku dan norma subyektif sebagai skala pengukuran yang diciptakan untuk menilai kepercayaan. Kelemahan penelitian pratama ini adalah peneliti tidak menkhususkan bidang e-commerce business to consumer (B2C) yang akan di teliti sedangkan $\mathrm{B} 2 \mathrm{C}$ dalam e-commerce sangat luas. Kelebihannya peneliti menggabungkan dengan teori-teori lain seperti dengan norma subyektif dan kontrol perilaku. Perbedaan dengan penelitian pada paper ini adalah pada pemilihan model penelitian. Penelitian ini bermaksud menguji 3 faktor yang mempengaruhi kepercayaan konsumen berdasarkan Trust Building Model (TBM) dalam e-commerce di Indonesia yang mengkhususkan pada bisnis ke konsumen pada bidang fashion saja sehingga penelitian ini diharapkan dapat memberikan hasil yang lebih spesifik yaitu khusus pada toko online fashion.

b) Pengaruh Dimensi Kepercayaan (Trust) terhadap Partisipasi Pelanggan E-Commerce [7]. Tinjauan pustaka yang kedua ini ditulis oleh Rofiq. Tujuan dari penelitian Rofiq ini adalah menguji pengaruh kepercayaan konsumen berdasarkan teori Mayer et al 1998. Kelemahannya adalah penelitian Rofiq hanya menyajikan kesimpulan yang dilihat dari sudut pandang sosial tanpa rekomendasi. Kelebihannya Rofiq menggabungkan banyak teori untuk membangun ukuran di masing-variabel. Perbedaannya dengan paper ini adalah Rofiq meneliti e-commerce secara general, sedangkan penelitian ini kusus pada ecommerce fashion; Rofiq menggunakan teori Mayer et al (1998); sedangkan penelitian ini menggunakan teori McKnight (2002) dengan TBM dan hasil dari penelitian ini adalah sebuah rekomendasi website e-commerce fashion yang dipercaya. Rekomendasi tersebut diharapkan akan melengkapi penelitian yang dilakukan rofiq karena diambil dari faktorfaktor yang belum diteliti oleh rofiq.

c) Al-Dwairi meneliti dalam jurnal berjudul "E-commerce Web Site Trust Factors: An Empirical Approach" [8]. Penelitian Al-Dwairi meneliti faktor-faktor yang mempengaruhi kepercayaan konsumen terhadap e-commerce melalui pendekatan-pendekatan empiris. Untuk mendapatkan data yang objektif, peneliti mensurvei sebanyak 261 responden. Penelitian ini adalah penelitian kuantitatif menggunakan skala Likert. Dari kuesioner yang diberikan kepada responden, peneliti mendapatkan data yaitu: $72,6 \%$ responden menyatakan enggan untuk mengungkapkan informasi sensitive mereka kepada web $e$ commerce. Kebalikannya 63,4\% menyatakan bahwa website dengan system keamanan akan menjadi website yang aman untuk bertransaksi. Di samping keamanan dan privasi, Al-Dwairi juga menyesuaikan dengan Technology Acceptance Model (TAM), dan responden setuju bahwa desain dan konten akan mempengaruhi kepercayaan konsumen terhadap e-commerce. Kelebihannya peneliti melakukan pendekatan empiris dengan teoriteori relevan untuk mendapatkan faktor-faktor yang valid. Kelemahannya Peneliti tidak menggambarkan indikator-indikator yang menjadi karakteristik masing-masing variabel Perbedaan dengan paper ini adalah paper ini berfokus pada konsumen e-commerce Indonesia. Tidak berfokus pada pencarian faktor-faktor pembangun kepercayaan $e$ commerce namun membuktikan teori yang sudah ada yang belum diuji pada penelitian AlDwairi. Personality Based Psychological Antecedents of Consumers' trust in E-commerce [4] 
d) Penelitian yang dilakukan oleh Azam ini mengidentifikasi faktor yang mempengaruhi kepercayaan konsumen e-commerce dari sudut pandang psikologis kaitannya dalam mengadopsi teknologi dan e-retailing. Azam mengembangkan sebuah model dengan menggabungkan 5 karakteristik kepribadian, yaitu: extraversion (pihak luar), neuroticism (emosi yang tidak stabil), agreeableness (kemauan untuk berbaik hati), consecientiousness (tanggung jawab), dan Openness to experiences (pikiran yang terbuka). Azam menguji model tersebut dengan survei yaitu dengan mengambil 140 mahasiswa universitas sebagai responden. Kelebihannya Azam menyebutkan dengan detail semua penjelasan mengenai masing-masing faktor, dan memberikan hasil pengujian hipotesis yang mendukung. Kelemahannya Sampel yang diambil dalam penelitian adalah hanya mahasiswa dari sebuah universitas. Keragaman responden tanpa membuka kesempatan untuk responden umum. Perbedaan dengan paper ini ada pada sudut pandang penelitian. Azam mengambil sudut pandang psikologi sedangkan penelitian pada paper ini mengambil sudut pandang informatika, model yang diacu pun berbeda. Responden yang diambil azam adalah masyarakat cina, sedangkan paper ini mengambil responden Indonesia. Kontribusi yang diharapkan dari paper ini adalah adanya hasil yang sesuai dengan masyarakat Indonesia dalam sudut pandang informatika.

e) Trust in Electronic Commerce: A New Model for Building Online Trust in B2C [9]. Penelitian yang dilakukan oleh Kamari ini mencoba menyajikan model pembangun kepercayaan dan kemudian menyarankan sebuah framework berdasarkan faktor-faktor yang ada. Dengan menempatkan kepercayaan sebagai sesuatu yang penting dalam ecommerce, maka model ini dapat membantu bisnis untuk membangun hubungan jangka panjang dengan konsumen. Kelebihan dari penelitian Kamari adalah menjelaskan secara mendalam mengenai masing-masing faktor. Seperti apa karakteristik desain yang baik atau useablity yang baik. Kelemahannya adalah belum ada pengujian mengenai model yang diusulkan. Perbedaan dengan paper ini ada dalam model pembangun kepercayaan. Penelitian ini menggunakan Trust Building Model (TBM) untuk menganalisis pengaruh antara faktor kepercayaan dengan perilaku e-commerce di Indonesia. Penelitian dalam paper ini diharapkan akan melengkapi penelitian Kamari dengan menguji salah satu faktor yang belum diuji yaitu pengaruh desain (dalam kualitas) sebuah website terhadap kepercayaan konsumen di Indonesia.

f) Pi dan Hsiu Li meneliti faktor yang mempengaruhi kepercayaan konsumen di taiwan dalam jurnal yang berjudul Factors that Affect Consumers' Trust and Continuous Adoption of Online Financial Services) [10]. Penelitian Pi dan Hsiu Li ini mengemukakan tentang kepercayaan konsumen dalam layanan keuangan online. Penelitian Pi dan Hsiu Li ini menelusuri bagaimana kepercayaan terhadap website mempengaruhi keinginan untuk terus menggunakan layanan keuangan online. Peneliti menjabarkan secara detail hasil analisis data yang dilakukan. Dan menyajikannya dalam bentuk kesimpulan yang sesuai. Kelemahan dalam penelitian Pi dan Hsiu Li ini adalah tidak adanya penjelasan mengenai perbedaan kepercayaan antara pelanggan yang sudah lama bertransaksi dengan yang belum pernah bertransaksi. Perbedaan dengan paper ini adalah Penelitian ini mengambil kasus pada e-commerce business to customer (B2C) pada toko fashion online bukan pada layanan keuangan online. Sampel survei adalah penduduk Indonesia bukan penduduk cina. Penelitian pada paper ini diharapkan akan bisa memberikan penjelasan mengenai bagaimana kepercayaan antara konsumen Indonesia yang sudah pernah bertransaksi dengan konsumen yang belum pernah bertransaksi.

Penelitian pada paper ini mengacu pada teori yang dikemukakan oleh McKnight pada tahun 2002 mengenai Trust Building Model (TBM). Trust Building Model (TBM) adalah sebuah model yang ditemukan dan dikembangkan untuk menggambarkan faktor yang mempengaruhi kepercayaan konsumen e-commerce. TBM menggambarkan bahwa sebelum konsumen $e$ commerce bersedia melakukan transaksi maupun bertukar informasi dengan suatu situs $e$ commerce ada beberapa faktor yang mempengaruhi, dalam penelitian ini akan membahas tiga 
faktor dalam TBM yang akan menjadi variabel penelitian yaitu: faktor perceived site quality (kualitas situs yang dirasakan), faktor perceived vendor reputation (reputasi vendor yang dirasakan), dan structural assurance (susunan keamanan)[5].

Perceived site quality (kualitas situs yang dirasakan) adalah persepsi akan kualitas situs toko online. Tampilan toko online dapat mempengaruhi kesan pertama yang terbentuk. Tampilan website yang professional memberikan rasa nyaman kepada pelanggan[5]. Membuat website yang atraktif dan menggunakan desain yang sesuai akan menambah kepercayaan konsumen[11]. Desain konten website mengarah pada komponen informasi dalam sebuah website, baik itu secara tekstual maupun secara grafis [12]. Kualitas informasi ditemukan sebagai faktor penting dalam kepercayaan online, kepuasan pelanggan, dan loyalitas [13].

Perceived vendor reputation (reputasi vendor yang dirasakan) merupakan suatu atribut yang diberikan kepada penjual berdasarkan pada informasi dari orang atau sumber lain. Reputasi dapat menjadi penting untuk membangun kepercayaan seorang konsumen terhadap penjual karena konsumen tidak memiliki pengalaman pribadi dengan penjual, reputasi dari mulut ke mulut yang juga menjadi kunci ketertarikan konsumen. Informasi positif yang didengar oleh konsumen tentang penjual dapat mengurangi persepsi risiko dan ketidakamanan ketika bertransaksi dengan penjual. Hal ini dapat membantu meningkatkan kepercayaan[5].

Structural assurance (susunan keamanan) adalah susunan yang membuat lingkungan terasa aman untuk konsumen. Pada level internet, susunan keamanan berarti percaya bahwa website yang dikunjungi mempunyai sistem keamanan atau susunan teknologi yang bisa menjamin bahwa bisnis yang berjalan dalam website akan berjalan aman dan sesuai rencana[5]. Susunan keamanan dapat dibagi menjadi 2 yaitu internal (IPeAs) dan eksternal (EPeAs). Internal meliputi kebijakan perusahaan seperti garansi uang kembali, kebijakan privasi, atau peraturan pengiriman barang. Keamanan internal ini tidak perlu dibuat oleh lembaga independen. Sedangkan dari segi ekternal susunan keamanan dapat di bangun dari sertifikasi keamanan dan privasi yang disediakan oleh pihak ketiga setelah lulus dari test dan evaluasi dari website [14]. Salah satu contoh keamanan pihak ketiga adalah 'BBBonline', 'TRUSTe', atau 'CyberTrust' yang kemungkinan akan memperngaruhi konsumen untuk percaya bahwa website vendor dapat dipercaya [15]. Structural Assurance dapat terbangun ke dalam situs e-commerce melalui kerja sama dengan pihak ketiga yang memiliki reputasi baik dalam masalah keamanan jaringan dan memberikan standar jaminan keamanan internet dengan web assurance seal seperti Verisign, TRUSTe, Good House Keeping dan CPA Web Trust [16].

Penelitian ini diharapkan dapat memberi kontribusi untuk web developer dalam membangun website toko online. Hasil penelitian ini akan menjadi dasar untuk memberikan rekomendasi kepada web developer kaitannya dengan komponen website toko online seperti apa yang perlu ada dalam membangun toko online fashion yang dapat dipercaya oleh konsumen di Indonesia berdasarkan variabel-variabel yang diteliti dalam penelitian ini.

Dalam penelitian ini terdapat hipotesis yang dikemukakan yaitu:

$\mathrm{H} 1$ : perceived vendor reputation (reputasi vendor yang dirasakan) berpengaruh positif terhadap faktor trust (kepercayaan) konsumen terhadap vendor e-commerce di Indonesia.

$\mathrm{H} 2$ : perceived site quality (kualitas situs yang dirasakan) berpengaruh positif terhadap trust (kepercayaan) konsumen terhadap vendor e-commerce di Indonesia.

H3: structural assurance (susunan keamanan) berpengaruh positif terhadap trust (kepercayaan) konsumen kepada vendor e-commerce di Indonesia.

H4: Faktor trust (kepercayaan) konsumen terhadap vendor berpengaruh positif terhadap behavioral (perilaku) konsumen untuk mau berbagi informasi pribadi dan atau bertransaksi pada situs e-commerce di Indonesia. 
TBM:

Berikut adalah gambaran hipotesis dalam penelitian ini dengan mengacu pada model

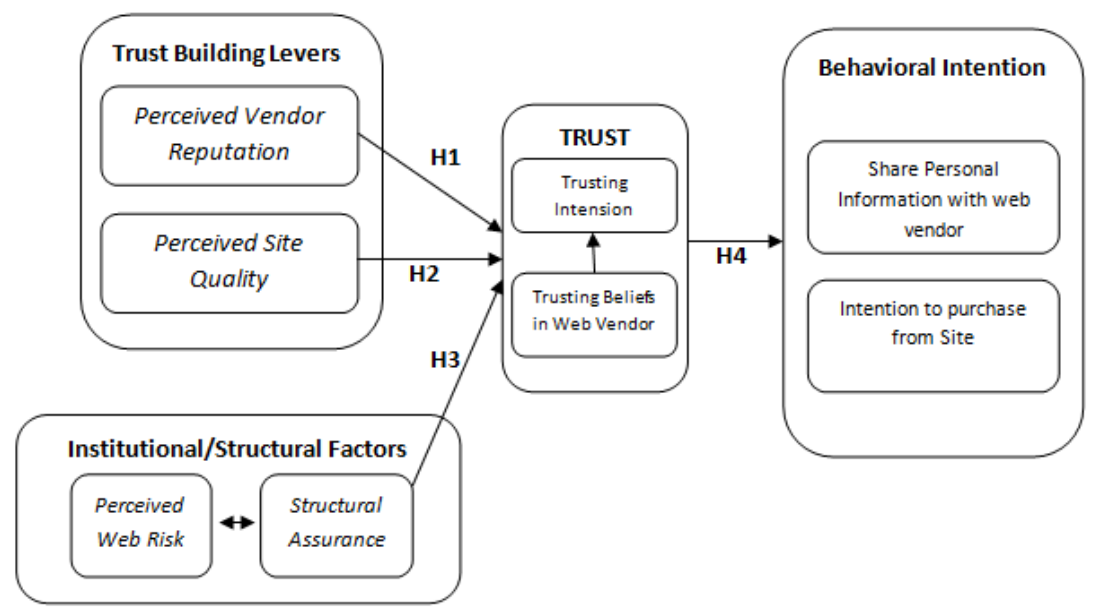

Gambar 1. Rancangan Hipotesis dengan Trust Building Model (TBM)

Dalam rancangan hipotesis tersebut peneliti melakukan penyesuaian model pada bagian perilaku konsumen. Berkaitan dengan batasan penelitian yang berfokus pada e-commerce $\mathrm{B} 2 \mathrm{C}$ pada bidang fashion, maka peneliti tidak meneliti variabel intention to follow vendor advice (keinginan untuk mengikuti saran/nasihat vendor) karena McKnight mengemukakan dalam penelitiannya bahwa variabel tersebut hanya untuk web vendor yang bergerak pada bidang kesehatan, hukum, dan financial advice.

\section{METODE PENELITIAN}

Populasi dalam penelitian ini adalah konsumen $e$-commerce toko online fashion yang sudah pernah maupun belum pernah bertransaksi online namun mempunyai keinginan untuk bertransaksi dikemudian hari, sehingga populasi dalam penelitian ini tidak terhingga jumlahnya dan tidak jelas batasannya oleh karena itu pengambilan sampel masuk dalam non probability sampling dengan teknik quota sampling dengan menentukan kuota sampel masing-masing pulau. Penentuan jumlah sampel didasarkan pada 2 hal yaitu pertama, pemilihan matrik estimasi yang dipilih dalam penelitian ini yaitu maximum likelihood estimation yang menyarankan menggunakan sampel antara 100-200. Kedua, didasarkan pada penargetan kuota berdasarkan pulau asal responden yang dilihat dari jumlah pengguna internet masing-masing pulau pada wilayah urban dari hasil survei yang dilakukan APJII tahun 2012, karena tidak semua penduduk Indonesia pernah menggunakan internet, maka dari itu untuk penduduk yang bukan pengguna internet, secara otomatis tidak akan bisa berkunjung pada situs toko online dan tidak akan bisa menjadi responden dalam penelitian ini sehingga pembobotan kuota diarahkan pada banyaknya pengguna internet.

APJII (Asosisasi Penyelengara Jasa Internet Indonesia) merupakan asosiasi yang berdiri pada tahun 1996, bertujuan untuk mengatur tarif jasa internet yang ada di Indonesia, membantu menyediakan jasa internet yang berkualitas bagi masyarakat Indonesia, memasyarakatkan internet dalam menunjang pengembangan sumber daya manusia di Indonesia dan membantu pemerintah dalam usaha memeratakan ekonomi tanah air melalui akses informasi dan komunikasi. Pada tahun 2012 APJII menyelenggarakan survey yang melibatkan sekitar 48.000.000 penduduk urban untuk mengetahui penetrasi pengguna internet di Indonesia. Hasil survei menunjukkan pertumbuhan penggunaan internet di Indonesia terus meningkat, angka penetrasi pengguna internet di wilayah urban pada tahun 2012 adalah sekitar 12.000.000 jiwa 
Citec Journal, Vol. 1, No. 2, Februari 2014 - April 2014

yang dipaparkan berdasarkan beberapa wilayah [17]. Tabel 1 merupakan ringkasan hasil survei pengguna internet Indonesia di wilayah urban dari APJII.

Tabel 1. Jumlah pengguna internet Indonesia wilayah urban

(Sumber: APJII, 2012)

\begin{tabular}{|l|l|r|r|}
\hline No & Pulau & $\begin{array}{r}\text { Jumlah } \\
\text { Populasi total (jiwa) }\end{array}$ & \multicolumn{1}{c|}{$\begin{array}{c}\text { Jumlah Pengguna } \\
\text { Internet (jiwa) }\end{array}$} \\
\hline 1. & Sumatera & 8.942 .000 & 2.076 .000 \\
\hline 2. & Jawa & 30.624 .000 & 8.318 .000 \\
\hline 3. & Kalimantan-Bali & 4.611 .000 & 1.114 .000 \\
\hline 4. & Sulawesi & 2.795 .000 & 802.000 \\
\hline 5. & Papua-maluku & 1.055 .000 & 215.000 \\
\hline & Jumlah & 48.027 .000 & 12.525 .000 \\
\hline
\end{tabular}

Tabel 2. Target sampel

\begin{tabular}{|l|l|r|}
\hline No & Pulau & Target sampel \\
\hline 1. & Sumatera & 33 \\
\hline 2. & Jawa & 133 \\
\hline 3. & Kalimantan-Bali & 18 \\
\hline 4. & Sulawesi & 13 \\
\hline 5. & Papua-maluku & 3 \\
\hline \multicolumn{2}{|c|}{ Target Jumlah Total Responden } & 200 \\
\hline
\end{tabular}

Analisis data pada penelitian ini menggunakan Pemodelan Persamaan Struktural (Structural Equation Modeling), biasa disingkat dengan SEM. Pemodelan Persamaan Struktural (SEM) dapat dideskripsikan sebagai suatu analisis yang menggabungkan pendekatan analisis faktor (factor analysis), model structural (structural model), dan analisis jalur (path analysis) [18]. Pada penelitian ini menggunakan software AMOS 22. 

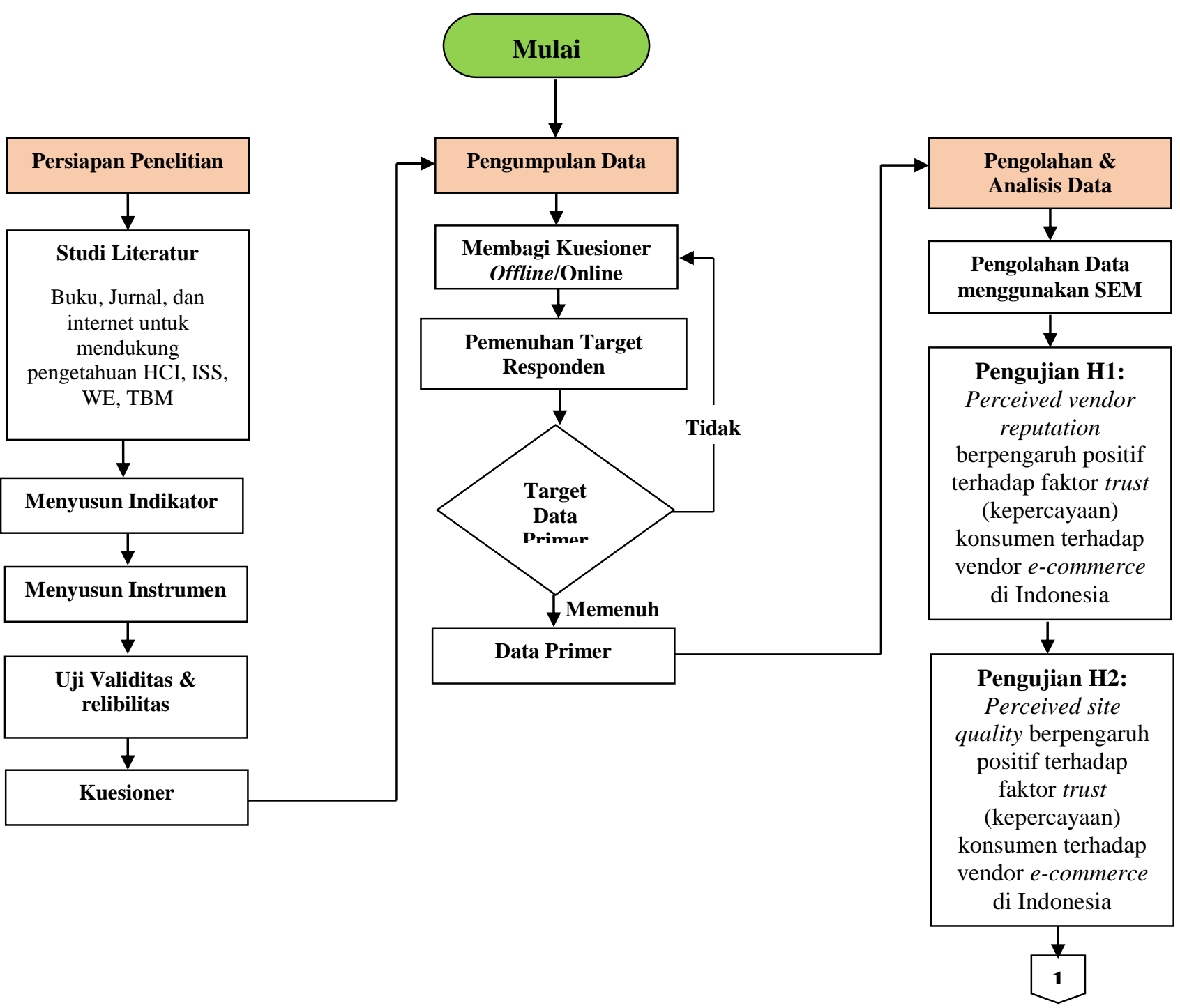

Gambar 2. Alur Penelitian 


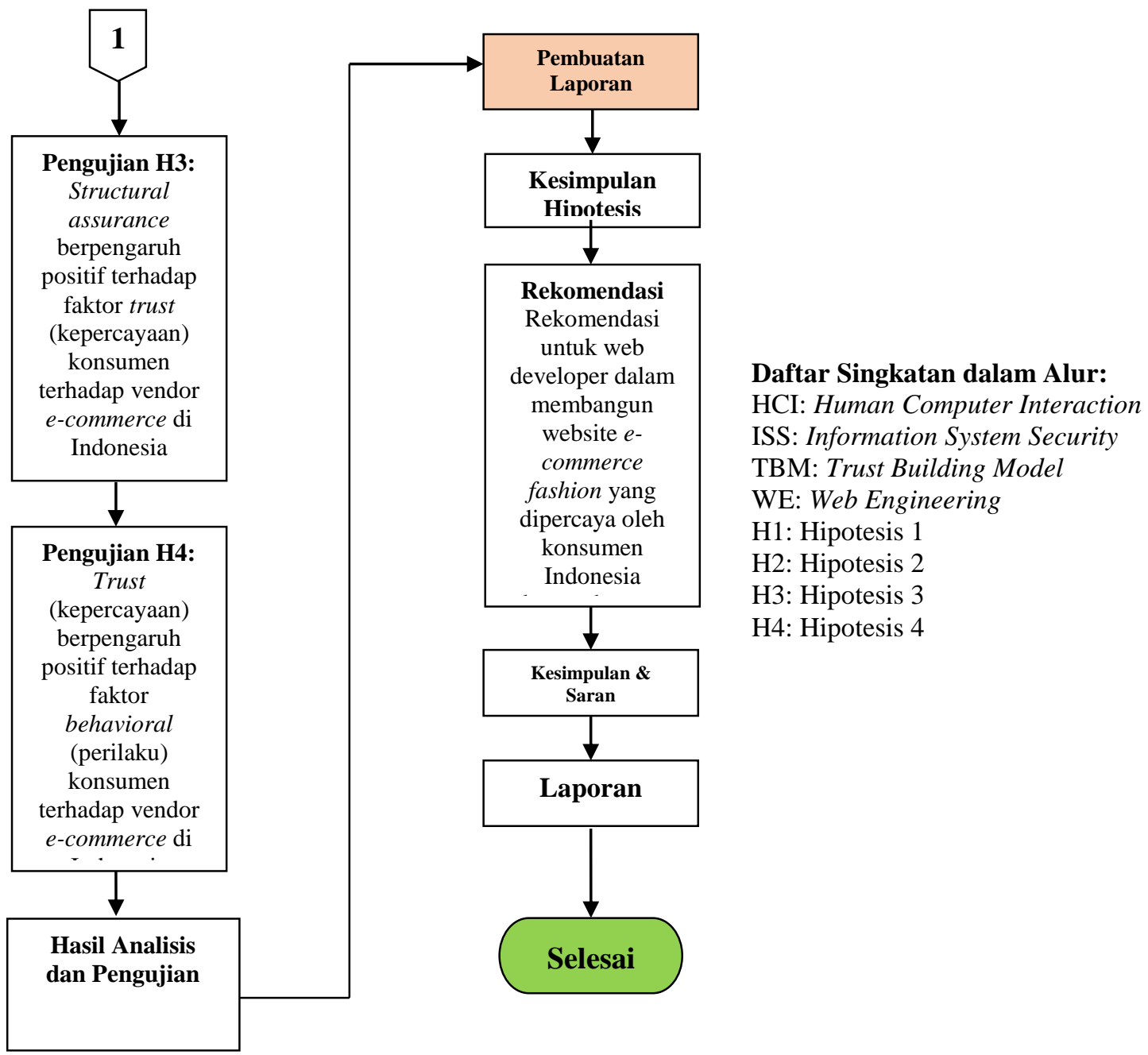

Gambar 3. (lanjutan) Alur penelitian

\section{HASIL DAN PEMBAHASAN}

Analisis data dalam penelitian ini menggunakan analisis model persamaan struktural (SEM) dibantu dengan program statistik AMOS versi 22. Besarnya ukuran sampel adalah 200 responden. Untuk memudahkan penyebutan, maka peneliti membuat singkatan istilah pada masing-masing variabel yang selanjutnya akan disebut dalam penelitian ini, yaitu Perceived Web Quality (PWQ), Perceived Vendor Reputation (PVR), dan Structural Assurance of The Web (SAW). PWQ mempunyai 8 indikator, PVR mempunyai 3 indikator, dan SAW mempunyai 4 indikator. 


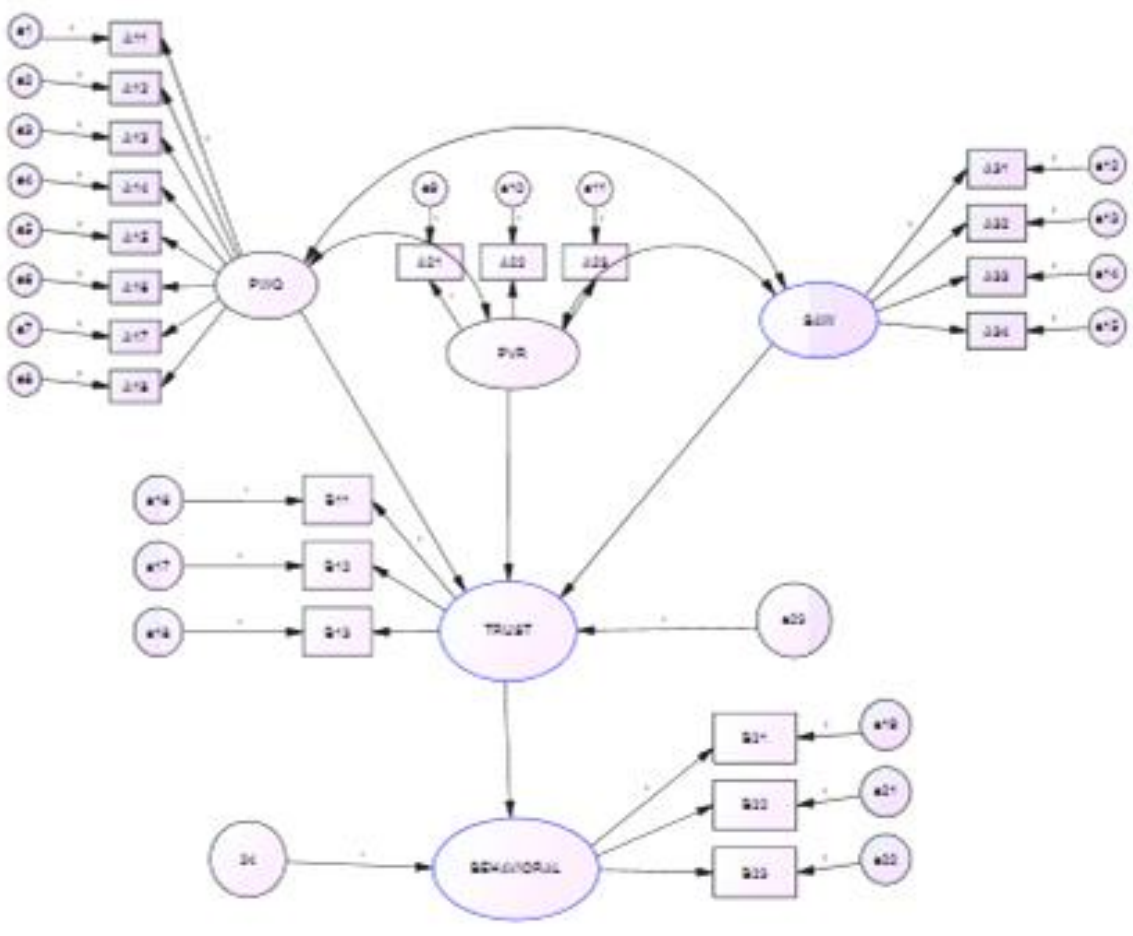

Gambar 4. Model Penelitian di Amos 22

Gambar 4 adalah gambar yang menunjukkan model awal penelitian ini. Dalam perhitungannya ada beberapa langkah untuk mendapatkan model yang benar-benar fit. Seperti dalam penelitian ini terdapat hasil evaluasi goodness of fit setelah melalui modifikasi, yang menyatakan bahwa nilai $\mathrm{CMIN} / \mathrm{DF}=1,217$ dimana kriteria untuk menjadi fit adalah $\leq 2,00$ sehingga model penelitian ini fit/baik.

Tabel 3. Kesesuaian Goodness of Fit

\begin{tabular}{|l|l|l|l|l|}
\hline No & \multicolumn{1}{|c|}{ Goodness of fit index } & \multicolumn{1}{c|}{ Kriteria } & Hasil & Keterangan \\
\hline 1 & Chi-square & Harus kecil & 81,546 & Fit \\
2 & Significant Probability & $\geq 0,05$ & 0,109 & Fit \\
3 & RMSEA & $\leq 0,08$ & 0,033 & Fit \\
4 & GFI & 0 sampai 1 & 0,949 & Fit \\
5 & AGFI & $\geq 0,90$ & 0,908 & Fit \\
6 & CMIN / DF & $\leq 2,00$ & 1,217 & Fit \\
7 & TLI & $\geq 0,90$ & 0,990 & Fit \\
8 & CFI & $\geq 0,90$ & 0,993 & Fit \\
9 & NFI & $\geq 0,90$ & 0,965 & Fit \\
11 & RFI & $\geq 0,90$ & 0,945 & Fit \\
12 & IFI & $\geq 0,90$ & 0,993 & Fit \\
13 & ECFI & Diantara saturated dan & 0,942 & Fit \\
\hline
\end{tabular}

Berdasarkan hasil pengujian yang telah tersaji pada tabel 1, diketahui dari kriteria yang ada diantaranya yang berada pada kondisi sangat baik (Fit). Dengan hasil ini maka secara keseluruhan dapat dikatakan bahwa model penelitian memiliki tingkat goodness of fit yang baik. 
Citec Journal, Vol. 1, No. 2, Februari 2014 - April 2014

ISSN: 2354-5771

\subsection{Uji Hipotesis}

Untuk pengujian hipotesis didasarkan atas analisis data penelitian dengan menggunakan analisis SEM, dengan cara menganalisis nilai regresi yang ditampilkan pada Tabel Regression Weights Analisis Structural Equation Modeling sebagai berikut:

Tabel 4. Hasil Uji Hipotesis

\begin{tabular}{|l|l|l|l|l|l|l|l|l|}
\hline \multicolumn{4}{|c|}{ Hipotesis } & Estimate & S.E. & C.R. & P & Keterangan \\
\hline H1 & TRUST & $<---$ & PVR & .039 & .160 & .243 & .808 & Tidak Signifikan \\
\hline H2 & TRUST & $<---$ & PWQ & .120 & .063 & 1.905 & .057 & Signifikan* \\
\hline H3 & TRUST & $<---$ & SAW & .517 & .169 & 3.057 & .002 & Signifikan \\
\hline H4 & BEHAVIORAL & $<---$ & TRUST & .462 & .110 & 4.199 & $* * *$ & Signifikan \\
\hline
\end{tabular}

*: tingkat signifikansi $10 \%$

Pengujian hipotesis ini adalah dengan menganalisis nilai Critical Ratio(CR) dan nilai Probability $(\mathrm{P})$ hasil analisis data, dibandingkan dengan batasan statistik yang disyaratkan, yaitu diatas 1,96 untuk nilai $\mathrm{CR}$ dan dibawah 0,05 untuk nilai $\mathrm{P}$ (probabilitas) jika tingkat signifikansinya 5\% dan 0,10 untuk tingkat signifikansi $10 \%$ dengan nilai CR diatas 1,28. Apabila hasil analisis data menunjukkan nilai yang memenuhi syarat tersebut, maka hipotesis penelitian yang diajukan dapat diterima. Secara rinci pengujian hipotesis penelitian akan dibahas secara bertahap sesuai dengan hipotesis yang telah diajukan. Pada penelitian ini diajukan empat hipotesis yang akan dibahas dibawah ini:

a) Hipotesis $1(\mathrm{H} 1)$ : Hipotesis 1 pada penelitian ini adalah perceived vendor reputation (reputasi vendor yang dirasakan) berpengaruh positif terhadap faktor trust (kepercayaan) konsumen terhadap vendor e-commerce di Indonesia. Berdasarkan analisis data primer diketahui bahwa nilai CR pada tabel di atas adalah sebesar 0,243 nilai $\mathrm{P}$ sebesar 0,808 . Hasil dari kedua nilai tersebut memberikan informasi bahwa pengaruh perceived vendor reputation terhadap behavioral dengan melalui trust positif namun tidak signifikan, karena tidak memenuhi syarat di atas 1,96 untuk CR dan di bawah 0,05 untuk nilai $\mathrm{P}$, dengan demikian dapat dikatakan bahwa hipotesis 1 penelitian ini ditolak. Nilai estimasi untuk PVR diperoleh 0,039, artinya bahwa dengan adanya peningkatan PVR maka akan meningkatkan behavioral karena adanya trust sebesar 3,9\% setiap satu persennya. Hasil pengujian hipotesis ini berbeda dengan hasil penelitian yang dilakukan oleh McKnight (2002) di mana reputasi vendor berpengaruh positif dan signifikan terhadap kepercayaan konsumen di Amerika pada website pemberi nasihat hukum. Temuan ini memberikan informasi bahwa reputasi vendor melalui website toko online fashion yang dibangun tidak menjadi fokus konsumen ketika ingin bertransaksi dengan toko online karena berdasarkan hasil penelitian ini pengaruh reputasi vendor tidak signifikan terhadap kepercayaan konsumen di Indonesia. Perbedaan hasil pengujian hipotesis bisa karena perbedaan fokus bidang objek yang diteliti, McKnight meneliti pada website pemberi nasihat hukum (LegalAdvice) sedangkan penelitian ini mengkhususkan diri pada bidang fashion sehingga reputasi vendor yang dibutuhkan untuk menumbuhkan kepercayaan konsumen pun menjadi berbeda.

b) Hipotesis 2 (H2): Hipotesis 2 dalam penelitian ini adalah perceived web quality (kualitas situs yang dirasakan) berpengaruh positif terhadap trust (kepercayaan) konsumen terhadap vendor e-commerce di Indonesia. Berdasarkan tabel 4 diketahui bahwa nilai CR adalah sebesar 1,905 dan nilai $\mathrm{P}$ sebesar 0,057. Hasil dari kedua nilai ini memberikan informasi bahwa adanya pengaruh positif dari PWQ terhadap trust dengan tingkat signifikansi 10\%, dengan demikian dapat dikatakan bahwa hipotesis 2 penelitian ini diterima. Nilai estimasi untuk kualitas kehidupan kerja diperoleh 0,120 , artinya bahwa dengan adanya peningkatan 
PWQ maka akan meningkatkan behavioral karena adanya trust sebesar $12 \%$ setiap satu persenya. Hasil pengujian hipotesis 2 ini menunjukkan bahwa kualitas website toko online fashion sangat penting dalam mempengaruhi konsumen untuk bertransaksi dengan website tersebut karena konsumen toko online fashion menilai produk berdasarkan tampilan virtual tanpa bisa menyentuhnya, dengan begitu persepsi konsumen terhadap sebuah website akan merepresentasikan kualitas vendor dan produk yang dijualnya. Semakin tinggi kualitas sebuah website maka akan semakin tinggi pula kepercayaan konsumen untuk bertransaksi dengan website tersebut. Kualitas website dapat diuraikan dengan pengukuran-pengukuran yang sudah ada pada indikator-indikator variabel Perceived Web Quality (PWQ).

c) Hipotesis 3 (H3): Hipotesis 3 pada penelitian ini adalah adanya pengaruh SAW terhadap behavioral dengan melalui trust. Berdasarkan analisis data diketahui bahwa nilai CR pada tabel 4 adalah sebesar 3,057 nilai $\mathrm{P}$ sebesar 0,002. Hasil dari kedua nilai ini memberikan informasi bahwa adanya pengaruh SAW terhadap behavioral dengan melalui trust, karena memenuhi syarat diatas 1,96 untuk CR dan dibawah 0,05 untuk nilai $\mathrm{P}$, dengan demikian dapat dikatakan bahwa hipotesis 3 penelitian ini dapat diterima. Nilai estimasi untuk SAW diperoleh 0,517, artinya bahwa dengan adanya peningkatan SAW maka akan meningkatkan behavioral karena adanya trust sebesar $51,7 \%$ setiap satu persenya. Hasil pengujian ini menunjukkan bahwa Structural Assurance of The Web (SAW) menjadi hal yang dipertimbangkan oleh konsumen. Penelitian ini membuktikan bahwa dalam perdagangan online sebelum konsumen memutuskan untuk percaya dan memilih website sebagai media pembelian produk fashion maka konsumen akan menilai sebuah website apakah aman atau tidak, dari sudut pandang konsumen sendiri. Karena semakin tinggi SAW suatu website, maka akan semakin tinggi juga kepercayaan konsumen terhadap website tersebut.

d) Hipotesis 4 (H4): Hipotesis 4 pada penelitian ini adalah adanya pengaruh Trust terhadap behavioral. Berdasarkan dari analisis data diketahui bahwa nilai CR pada tabel 4 adalah sebesar 4,199 nilai P sebesar 0,000. Hasil dari kedua nilai ini memberikan informasi bahwa adanya pengaruh Trust terhadap behavioral, karena memenuhi syarat diatas 1,96 untuk CR dan dibawah 0,05 untuk nilai $\mathrm{P}$, dengan demikian dapat dikatakan bahwa hipotesis 4 penelitian ini dapat diterima. Artinya bahwa trust variabel mediator mampu memberikan pengaruh positif terhadap suatu hubungan diantara ketiga variabel, sehingga trust mampu memberikan pengaruh terhadap perilaku yang akan diambil oleh konsumen. Hasil pengujian hipotesis 4 ini menunjukkan bahwa kepercayaan sangat mempengaruhi konsumen untuk mengambil tindakan seperti memutuskan untuk bertransaksi dengan website yang konsumen kunjungi dan dianggap dapat dipercaya. Sehingga semakin tinggi kepercayaan konsumen terhadap website e-commerce fashion, maka akan semakin tinggi pula keinginan untuk bertransaksi maupun merekomendasikan website tersebut kepada orang lain.

Pada pengujian hipotesis $\mathrm{H} 2, \mathrm{H} 3, \mathrm{H} 4$ ini senada dengan apa yang dikemukakan McKnight (2002)[5] yaitu kualitas website dan susunan keamanan sangat berpengaruh terhadap kepercayaan, begitu pula kepercayaan berpengaruh terhadap perilaku yang akan diambil oleh konsumen. Temuan dalam penelitian ini adalah adanya tingkat signifikansi yang berbeda dengan penelitian yang dilakukan McKnight. Pada penelitian McKnight disebutkan bahwa perceived web quality (kualitas website yang dirasakan) lebih signifikan berpengaruh terhadap kepercayaan dibanding structural assurance (susunan keamanan) sedangkan pada penelitian ini (bagi konsumen toko online fashion Indonesia) hasilnya berkebalikan yaitu susunan keamanan yang paling signifikan. Hal ini membuktikan bahwa adanya perbedaan bidang objek penelitian dan kebudayaan konsumen bisa mempengaruhi perbedaan tingkat signifikansi dari masingmasing variabel.

\subsection{Rekomendasi}

Hasil pengujian hipotesis di atas mendasari peneliti untuk memberikan rekomendasi kepada web developer dalam membangun website toko online fashion yang dapat dipercaya. 
Rekomendasi dalam penelitian ini adalah menyangkut hal-hal yang perlu dilakukan berdasarkan hasil dari penelitian ini. Rekomendasi ini ditujukan kepada web developer (pengembang web) khususnya untuk pengembangan website toko online fashion Bussiness to Consumer (B2C). Rekomendasi dibagi menjadi 2 aspek pembahasan, yaitu: a) Susunan Keamanan dan b) Kualitas Website. Uraian pembahasan rekomendasi secara rinci akan dibahas sebagai berikut:

a) Susunan Keamanan

Penelitian ini membuktikan bahwa konsumen akan semakin percaya dengan sebuah website toko online jika website toko online tersebut dinilai aman dari sudut pandang konsumen itu sendiri. Beberapa rekomendasi agar website semakin dipercaya oleh konsumen adalah dengan memperhatikan hal-hal sebagai berikut:

Sebaiknya ketika pengembang web membangun sebuah toko online, akan lebih baik jika website tersebut mempunyai bukti jaminan keamanan yang mix dengan jaminan privasi. Website merupakan situs jual beli online yang sudah lulus dalam sertifikasi jaminan keamanan yang dilakukan oleh pihak ketiga. Jaminan keamanan tersebut dapat terlihat dan diketahui oleh konsumen dengan meletakkan logo/syimbol dari pihak ketiga pada halaman web. Pemberi lisensi lulus jaminan keamanan ini adalah perusahaan seperti TRUSTe Privacy seal, BBBOnline, dan Verisign security.

Rekomendasi selanjutnya adalah adanya security disclosure, yaitu informasi mendetail mengenai bagaimana SSL digunakan untuk mengamankan transaksi, mengamankan keuangan, dan menunjukkan kepada konsumen tentang SSL simbol. Pada poin ini pengembang web diharapkan memberikan penjelasan mengenai simbol atau logo keamanan tersebut dengan cara pop up window setelah logo itu diklik. Dan sekaligus menunjukkan bahwa logo sertifikasi keamanan dan privasi tersebut asli.

b) Kualitas Website

Berdasarkan hasil penelitian ini diperoleh bahwa kualitas website menjadi hal yang penting dalam mempengaruhi kepercayaan konsumen. Hal tersebut menjadi dasar untuk memberikan rekomendasi kepada web developer untuk memperhatikan hal-hal sebagai berikut:

Sebaiknya website mempunyai halaman khusus untuk memberikan informasi tentang perusahaan. Halaman ini bisa berupa halaman about. Halaman tersebut nantinya akan memberitahukan konsumen bagaimana mengontak penjual. Untuk lebih meyakinkan konsumen, maka sebaiknya disertakan juga hal-hal yang dapat membuat konsumen percaya bahwa penjual memang benar-benar ada dan memiliki barang yang mereka jual seperti memaparkan alamat kantor dan nomor telepon kantor, bukan nomor telepon pribadi.

Pada halaman utama sebuah website yang ingin dipercaya oleh konsumen, sebaiknya memberikan informasi secara jelas hal-hal yang berhubungan dengan informasi pratransaksi. Seperti: tentang garansi jika barang tidak sesuai dengan apa yang terdisplay dalam website, maka penjual akan mengembalikan uang yang sudah dikirim. Selain garansi, website juga perlu mencantumkan informasi biaya seperti: gratis biaya pengiriman hanya di kota yang sama, agar pembeli dari kota berbeda tidak merasa terbohongi karena mereka harus membayar biaya pengiriman, termasuk informasi jika ada keterlambatan pengiriman lebih dari 7 hari misalnya, maka penjual akan mengembalikan uang pembeli. Informasi seperti yang disebutkan di atas dapat di berikan pada halaman utama sebuah website toko online berupa image yang dapat menggambarkan informasi tersebut dengan di klik, dan atau ketika kursor didekatkan.

Sebaiknya web developer membuat website yang terlihat professional. Menurut Nah et al (2002) desain professional adalah desain yang jauh dari error [19]. Sesuai dengan sudut pandang konsumen, website professional dalam penelitian ini adalah website yang berjalan lancar secara teknis ketika konsumen mengakses website tersebut. Seperti tidak ada link yang rusak, gambar yang tidak terdisplay, dan tidak ada skrip/coding yang error.

Rekomendasi mengenai kualitas website yang ketiga adalah mengenai kemudahan konsumen dalam mencari informasi dari website. Hal ini menyangkut bagaimana produk dikelompokkan dan bagaimana website memberikan kemudahan kepada konsumen dalam 
mencari produk. Oleh karena itu maka web developer sebaiknya membubuhkan menu yang berisi kategori produk yang dijual di website sehingga akan memudahkan konsumen dalam navigasi. Selain menu tersebut, sebaiknya ada pula menu search yang dapat digunakan untuk mencari produk dengan mengetikkan kata kunci.

Sebaiknya dalam pembuatan website e-commerce fashion, pengembang web juga memperhatikan kombinasi warna yang akan dipadukan. Ketika konsumen melihat tulisan yang susah dibaca karena kontras warna yang buruk antara background dengan tulisan maka akan membuat konsumen berasumsi bahwa website tidak bagus. Hal ini senada dengan teori dari Everard et al (2005) yang mengatakan bahwa website dikatakan good style jika mempunyai kontras yang baik pula [20].

\section{KESIMPULAN}

Kepercayaan konsumen e-commerce toko online fashion di Indonesia sangat dipengaruhi oleh kualitas website dan susunan keamanan yang tersaji melalui website, sedangkan reputasi vendor melalui website tidak signifikan mempengaruhi konsumen untuk bisa lebih percaya pada suatu vendor toko online fashion. Dari segi kualitas website penelitian ini menemukan bahwa adanya pengaruh positif dan signifikan antara kualitas website terhadap kepercayaan konsumen. Hal ini berarti perlu adanya perhatian dalam mendesain sebuah website toko online. Selain kualitas website, terdapat pula susunan keamanan yang juga berpengaruh pada kepercayaan konsumen, dan pengaruh tersebut signifikan. Susunan keamanan menurut konsumen dalam penelitian ini adalah adanya simbol dan penjelasan spesifik tentang garansi sebelum konsumen melakukan transaksi.

Terdapat temuan dalam penelitian ini yaitu adanya perbedaan tingkat kepercayaan konsumen e-commerce toko online fashion di Indonesia antara konsumen yang sudah pernah bertransaksi dengan konsumen yang belum pernah bertransaksi. Konsumen yang sudah pernah bertransaksi memiliki kepercayaan lebih tinggi dibanding konsumen yang belum pernah. Hal ini berarti selain faktor-faktor yang telah diteliti dalam penelitian ini, terdapat pula faktor lain meningkatkan kepercayaan konsumen e-commerce toko online fashion Indonesia yaitu faktor pengalaman bertransaksi. Hasil penelitian ini membuktikan bahwa kepercayaan mampu memberikan pengaruh positif terhadap suatu hubungan diantara ketiga varibel, sehingga kepercayaan mampu memberikan pengaruh terhadap perilaku yang akan diambil oleh konsumen. Implikasinya bagi para vendor e-commerce agar mempunyai strategi dalam pengembangan website toko online dan penelitian ini juga dapat menjadi acuan bagi para web developer dalam pengembangan website toko online.

\section{SARAN}

Diharapkan pada penelitian berikutnya akan didapatkan temuan baru terkait website yang dapat dipercaya konsumen. Klasifikasi e-commerce tidak hanya pada business to consumer (B to $\mathrm{C}$ ), maka dari itu, diperlukan penelitian lebih lanjut mengenai klasifikasi e-commerce yang lain seperti business to business (B to B) dan Consumer to Consumer ( $\mathrm{C}$ to $\mathrm{C}$ ).

\section{DAFTAR PUSTAKA}

[1] Indrajit, R. E., 2001, E-Commerce: Kiat dan Strategi Bisnis di Dunia Maya, PT. Elek Media Komputindo, Jakarta.

[2] Thomas, W. S., Norman, M. S., 2009, Kewirausahaan dan Manajemen Usaha Kecil, Salemba Empat, Jakarta 
[3] Moorman, C., 1992, Relationships between Providers and Users of Market Research: The Dynamics of Trust Within and Between Organizations, Journal of Marketing Research, hal 314-328.

[4] Azam, A., 2013, Personality Based Pcychological Antecedents of Consumers Trust in ECommerce, Journal of WEI Business and Economics, hal 31-40.

[5] McKnight, D. H., Chervany, N. L., 2001. What Trust Means in E-Commerce Customer Relationships: An Interdisciplinary Conceptual Typology, International Journal of Electronic Commerce, hal 35-59.

[6] Pratama, Y. N., 2012, Pengaruh Privasi dan Kepercayaan terhadao Internet pada Perilaku Pembelian Online, Tesis, Universitas Gajah Mada, Yogyakarta

[7] Rofiq, A., 2007. Pengaruh Privasi dan Kepercayaan (Trust) terhadap Partisipasi Pelanggan E-Commerce, Tesis, Program Studi Manajemen Universitas Brawijaya, Malang.

[8] Aldwairi, R. M., 2013, E-Commerce Web Site Trust Factors: An Empirical Approach, Contemporary Engineering Sciences, hal 1-7.

[9] Kamari, F., Saeid, 2012, Trust in Electronic Commerce: A New Model for Building Online Trust in B2, European Journal of Business and Management, hal 125-135.

[10] Pi, S. M., Liao, H. L., Chen, H. M., 2012, Factors that Affect Consumers' Trust and Continous Adoption of Online Financial Services. International Journal of Business and Management, hal 108-119.

[11] Karimov, F. P., Brengman, M., Hove, L. V., 2011. The Effect of Website Design Dimension on Initial Trust: A Synthesis of The Empirical Literature. Journal of Electronic Commerce Research, hal 272-301.

[12] Wang, Y. D., Emurian, H. H., 2005, Trust E-Commerce-Consideration of Interface Design Factors, Journal of Electronic Commerce in Organizations, hal 42-60.

[13] Kim, S., Stoel, L., 2004, Apparel Retaillers: Website Quality Dimension and Saticfaction, Journal of Retailing and Consumer Services, hal 109-117.

[14] Bahmanziari, T., Odom, M. D., Ugrin, J. C., 2009, An Experimental of the Effect of Internal and External e-Assurance on Initial Trust Formation in B2C E-Commerce, International Journal of Accounting Information System, hal 152-170.

[15] Hu, X., Wu, G., Zhang, H., 2010, The Effect of Web Assurance Seals on Consumers' Initial Trust in Online Vendor: A Functional Perspective. Decision Support Systems, hal 407-418.

[16] Gefen, D., Karahanna, Straub, 2003, Trust and Tam in Online Shopping: An Integrated Model, MIS Quartery, hal 51-90.

[17] APJII (Asosiasi Penyelenggara Jasa Internet Indonesia). 2012. Profil Pengguna Internet Indonesia. Survey Report.

[18] Sugiyono, 2012, Statistika untuk Penelitian, CV. Alfabeta, Bandung.

[19] Nah, F., Davis, S., 2002, HCI Research Issues in E-Commerce, Journal of Electronic Commerce Research, hal 98-113.

[20] Everard, A, Galleta, D., 2005, How Presentation Flaws Affect Perceived Site Quality, Trust, and Intention to Purchase from an Online Store, Journal of Management Information System, hal 56-95. 